\title{
Propostas Alternativas de Gestão Hospitalar e o Protagonismo dos Trabalhadores: por que as coisas nem sempre acontecem como os dirigentes desejam?
}

\section{Alternative Proposals for Hospital Management and the Protagonism of Workers: why do things not always happen as expected by the leaders?}

Luiz Carlos de Oliveira Cecílio

Médico Sanitarista da Secretaria de Estado da Saúde de São Pau-

lo, doutor em Saúde Coletiva e professor da pós-graduação em

Saúde Coletiva do Departamento de Medicina Preventiva e So-

cial da Unicamp.

E-mail: cecilioluizœuol.com.br

Taniella Carvalho Mendes

Médica Sanitarista da Secretaria Municipal de Saúde de Campinas.

\section{Resumo}

O artigo apresenta e discute o estudo de observação realizado em um hospital público municipal, com o objetivo de caracterizar como os trabalhadores, no seu cotidiano e com suas práticas concretas, se apropriam de uma determinada política institucional estabelecida pela direção, em particular a implementação de novas formas de se fazer a gestão e as diretrizes para a reorganização do processo de trabalho. 0 estudo permitiu mostrar que, na micropolítica do hospital, as diretrizes da direção sofrem uma espécie de "distorção" ao atravessarem o denso campo de forças resultante do protagonismo dos trabalhadores e de suas incontáveis estratégias visando a defesa dos seus espaços de autogoverno. Tais diretrizes são reinterpretadas, ressignificadas e traduzidas em práticas que mais parecem manter certos instituídos - em particular a ainda expressiva autonomia da prática médica e das relações de dominação dos médicos em relação às outras corporações - do que reiventar, efetivamente, as relações existentes na vida hospitalar.

Palavras-chave: Gestão; Poder; Micropolítica; Organização Hospitalar; Processo de Trabalho. 
Abstract

The article presents and discusses the observational study performed in a public city hospital, with the objective of characterizing how workers, in their daily activities and with their concrete practices, take over a certain institutional policy established by the administration, particularly the implementation of new ways of managing and the guidelines to reorganize the working process. The study allowed showing that, in the hospital micropolitics, the administrative guidelines undergo a certain "distortion" as they cross the dense field of forces that result from the workers' protagonism and their uncountable strategies aimed at defending their self-government universe. Such guidelines are reinterpreted, resignified and translated into practices which rather seem to maintain certain institutionalized aspects of organizational life - particularly to the still expressive autonomy of the medical practice and of the domination relationship of the doctors in relation to other corporations - than effectively reinvent hospital life relations.

Key Words: Management; Power; Micropolitics; Hospital Organization; Work Process

\section{Introdução}

A década de 1990 foi rica em propostas e experiências de mudanças de modelo de gestão nos hospitais públicos e privados brasileiros (Schiesari, 2003; Costa e cols, 200o; Lima; Malick e Teles, 2001). No caso do setor público, as motivações para tal movimento, bastante heterogêneo na sua composição, podem ser explicadas tanto pela necessidade de se fazer frente às dificuldades gerenciais próprias da administração pública, em particular os complicados e burocratizados processos de provimento de todo o tipo de insumos para o funcionamento rotineiro do hospital, como por um ideal de se construir serviços que oferecessem melhor assistência aos seus usuários, na perspectiva da consolidação do SUS no nosso país.

No presente artigo, analisamos os esforços de mudanças no modo de se fazer a gestão em um hospital público municipal, escolhido para o presente estudo pelas características bastante inovadoras do modelo de gestão adotado e pela experimentação de novas formas de se pensar a organização do processo de trabalho. A direção é composta por servidores da prefeitura, em sua maioria, e por alguns assessores, tendo quase todos um histórico de luta pela consolidação do Sistema Único de Saúde (SUS) no nosso país. Um grupo de direção bastante experiente que traz, em sua bagagem, muitas idéias de "dispositivos gerenciais", que compõem uma "caixa de ferramenta gerencial” (Merhy, 2002), em princípio com muita potência para influenciar a organização do processo de trabalho do hospital e o modo de se fazer a coordenação das atividades.

Foram inúmeros os dispositivos gerenciais que a direção do hospital lançou mão durante sua gestão, tendo como objetivo impactar positivamente na qualificação do cuidado ofertado aos usuários. Tais dispositivos podem ser agrupados em três blocos: os relativos ao modelo de gestão; os que se ocupam de mudanças na organização da assistência e, por fim, aqueles referentes ao aperfeiçoamento do controle social. Não temos a pretensão, neste trabalho, de fazer uma avaliação global do hospital e os eventuais resultados positivos que possam ser creditados a uma nova forma de se fazer a gestão. Pretendeu-se, metodologicamente, realizar um mergulho na micropolítica do hospital com o objetivo de caracterizar como tais dispo- 
sitivos propostos pela direção são percebidos e apropriados pelos trabalhadores.

No primeiro bloco de dispositivos, qual seja, aqueles relativos ao modelo de gestão, em particular os que apontam para um novo modo de se fazer a coordenação do hospital, destacamos o novo arranjo do organograma do hospital, no qual se destaca, antes de mais nada, a criação de colegiados gestores em todos os seus diversos níveis de decisão. Os espaços colegiados gestores criados foram:

1- O COLEGIADO GESTOR DE CADA UNIDADE composto pelos trabalhadores da unidade e coordenado pelo coordenador gerencial e o gerente de cada unidade. Entre as suas funções está previsto: "Elaborar plano de ação; Realizar a gestão operacional; Explicitar $e$ trabalhar as diferenças entre membros da equipe $e$ dela com atores externos; Organizar a educação continuada; Aprovar ações e tarefas a serem colocadas em prática. É subordinado ao Colegiado Gestor do Hospital e apresenta uma composição multiprofissional" (Documento oficial do hospital, 2002)

2- O COLEGIADO GESTOR DO HOSPITAL composto por coordenações gerenciais de unidades de apoio (imagem e radioterapia, laboratório e setor de transfusão, gestão com pessoas, suprimentos, manutenção, apoio administrativo, técnica hospitalar, finanças, informação), pelas coordenações gerenciais de unidades assistenciais, pelo coordenador da comissão de residência médica, pelo diretor clínico e coordenado pelo presidente do hospital. Entre suas atribuições está previsto: "Integrar os planos específicos das unidades de serviço, no sentido de construir o plano diretor do hospital, respeitadas as diretrizes básicas do Conselho Local de Saúde, do Conselho Municipal de Saúde e do Sistema Único de Saúde; Constituir-se em espaço de negociação e articulação entre as unidades de serviço, no sentido de otimizar os recursos existentes e alcançar crescente melhoria na qualidade dos serviços prestados; Normalizar as ações de interesse geral da instituição, tomando decisões e estabelecendo compromissos mútuos; Implantar um Sistema de Petição e Prestação de Contas, acompanhando os resultados obtidos com os serviços prestados, tanto nas questões assistenciais, como em relação ao custo/benefício; Espaço para avaliação e prestação de contas do andamento do projeto e deliberação de questões gerais do hospital; Garantir a comunicação entre as várias instâncias, no que diz respeito aos compromissos institucionais e aos novos projetos; Ser agente da democratização institucional, garantindo a participação do conjunto dos profissionais que atuam no hospital, na formulação de propostas para a operacionalização das políticas gerais;Reunir-se periodicamente (quinzenalmente), com pauta previamente definida e com objetivo de cumprir as atribuições acima descritas". (Documento oficial do hospital, 2002).

3- O NÚCLEO EXECUTIVO composto pelo diretor-presidente do hospital, pelo diretor técnico, diretor administrativo, pelo grupo de apoio à gestão (responsável pelo desenvolvimento dos gestores do hospital), pelos diretores das linhas de cuidado dos pacientes cirúrgicos, clínicos e externos e de apoio diagnóstico (entende-se linha de cuidado como um arranjo gerencial para coordenar as unidades assistenciais que compõem o fluxo do paciente dentro do hospital), coordenadorias estratégicas (gestão com pessoas, informação e ações da saúde coletiva, apoio técnico hospitalar), referência de enfermagem, ouvidoria. Entre suas atribuições está previsto:"Promover a definição das diretrizes institucionais e velar por sua efetiva aplicação; Processar e enfrentar os macro-problemas; Gestão executiva do projeto institucional com funções de coordenação e direção do conjunto dos Apoiadores e Assessores, Coordenações e Gerências das unidades, entendidas como unidades com equipe multiprofissional e produtos claramente identificáveis e específicos; Constituir-se em instância de mediação entre a Secretaria Municipal de Saúde, o Conselho Local de Saúde e o Colegiado Gestor na reformulação de diretrizes gerais e operacionais para o projeto do hospital; Gerenciar a agenda estratégica da instituição, cuidando para que os imprevistos que se apresentam no cotidiano não se sobreponham aos objetivos maiores do projeto, mas sejam processados dentro do seu âmbito; Manter interlocuções interna e externa à instituição, analisando as oportunidades existentes $e$ propondo os redirecionamentos necessários; Observar a pauta das reuniões do Colegiado Gestor e processar assuntos a serem discutidos; Organizar o processo de planejamento e avaliação institucional; Encaminhar decisões que não possam aguardar a reunião ordinária do Conselho Gestor; Implementar as decisões do colegiado gestor e do conselho local de 
saúde; Reunir-se semanalmente, com pauta previamente definida e com objetivo de cumprir as atribuições acima descritas" (Documento oficial do hospital, 2002).

A proposta de mudança do organograma do hospital teve o intuito, em princípio, de descentralizar as decisões da direção para diversos níveis dentro do hospital. O investimento intenso para a adoção da cogestão em todos os espaços formais de decisão do hospital pretendia propiciar aos servidores a possibilidade de participar do planejamento de suas ações, sentindo-se mais sujeitos da gestão do hospital. Houve a preocupação de se estabelecer, da forma mais clara possível, as atribuições de cada novo espaço de gestão colegiada, bem como de garantir a capacitação de todos os técnicos que assumiram cargos de gestores. Ainda no bloco dos novos dispositivos gerenciais, foi proposta a seguinte forma de coordenação das unidades assistenciais:

1. O COORDENADOR GERENCIAL, com as seguintes atribuições: "Garantir, no seu âmbito de atuação, os princípios de defesa da vida, da humanização da assistência e do direito à saúde; Implantar a gestão participativa, instituindo e fazendo funcionar o colegiado da unidade; Convocar, preparar e coordenar as reuniões do colegiado; Conduzir o processo de implementação das decisões do colegiado; Coordenar a definição, com o colegiado, do plano de ação de sua área; Acompanhar sistematicamente a implantação e concretização desse plano; Organizar o processo de trabalho de sua unidade, objetivando a integração da equipe, a atuação multi-profissional e a centralização nas necessidades do usuário; Representar a unidade junto à diretoria executiva; Gerir o pessoal de sua unidade; Supervisionar a elaboração das escalas de trabalho; Supervisionar o controle de freqüencia; Administrar problemas e conflitos inerentes ao cotidiano do trabalho em equipe; Identificar necessidades de educação continuada, capacitação e aprimoramento no âmbito de sua unidade, providenciando as medidas pertinentes; Levantar e acompanhar os dados de produção e controle de qualidade; Efetuar a comunicação lateral com as outras unidades de serviço e com outros órgãos da administração, visando solução de problemas e melhoria dos resultados; Fazer acompanhamento dos custos da unidade, cuidando de sua otimização e contribuindo para a auto-suficiência financeira da instituição; Tomar decisões emergenciais, com base em diretrizes já definidas; Ser o elo de ligação com atores externos, principalmente usuários; Fazer previsão, provisão de controle de material, equipamentos e insumos; Promover a análise prévia, pelo respectivo colegiado dos temas a serem discutidos pelo colegiado gestor; Acompanhar e supervisionar a atuação do(s) gerente(s) e do(s) apoio(s) técnico(s) gerencial(is) de sua unidade, quando for o caso" (Documento oficial do hospital, 2002).

2. o GERENTE, com as seguintes atribuições:"Assume, em conjunto com o coordenador gerencial, as responsabilidades da unidade de produção, auxiliando-o no que se fizer necessário; Responsabiliza-se por uma determinada área, quando terá como atribuições as mesmas do coordenador gerencial, no que couber; Responde diretamente ao respectivo coordenador gerencial, com quem deverá pactuar a linhas de atuação, atribuições específicas, limite de decisão e de tudo mais que fornecessário, inclusive as formas de prestação de contas." (Documento oficial do hospital, 2002) 3. A REFERÊNCIA TÉCNICA, com as seguintes atribuiÇões:"São investidos no papel de apoiadores técnicos, trabalhadores que sejam reconhecidos, profissional e legalmente, como tendo domínio de determinado campo de saber; Sua autoridade é técnica e não gerencial; Desencadear processos de reflexão crítica sobre as práticas utilizadas e sobre a integralidade da atenção; Cuidar da educação permanente em serviço; Participar da capacitação das equipes que a necessitarem, em suas respectivas áreas de competência; Apoiar tecnicamente, sem ascendência hierárquica, a gestão da unidade; Apoiar matricialmente os coordenadores gerenciais e a diretoria executiva, tanto na elaboração da pauta das reuniões, quanto ao processamento de problemas identificados como prioritários para a sua agenda; Deve ter íntima relação com a residência médica, quando for o caso; Para exercer esta função, o trabalhador deve ter disponibilidade para horizontalização da jornada de trabalho" (Documento oficial do hospital, 2002).

No segundo bloco de dispositivos propostos pela direção, estão aqueles voltados para a qualificação da assistência. Entre eles, destacam-se:

1. o PRONTUÁRIO INTEGRADO visando fortalecer o 
trabalho em equipe e a qualificação da assistência através da orientação dos registros, a partir dos problemas e de questões relevantes do paciente nos âmbitos bio-psico-social. Ele deverá ser preenchido por todos os profissionais de saúde, extinguindo os demais prontuários por corporação.

2. a ORGANIZAÇÃO DE EQUIPES MULTIPROFISSIONAIS DE REFERÊNCIA NAS ENFERMARIAS, com o objetivo de se estabelecer vínculo e responsabilização pelo cuidado dos pacientes durante o seu período de internação.

3. a adoção de PROTOCOLOS DE ATENDIMENTO, que pudessem padronizar as ações em saúde realizadas no hospital, disputando, em alguma medida, com a autonomia das ações dos profissionais.

4. uma SISTEMÁTICA DE AVALIAÇÃO DE RISCO dos usuários aguardando atendimento no pronto-socorro, visando garantir a priorização do atendimento dos casos avaliados como de maior gravidade, sempre com o intuito de implementar um cuidado centrado nas necessidades dos usuários. Este dispositivo foi implantado na gestão anterior, tendo sido assumido como estratégia assistencial pela atual direção.

O grupo dos dispositivos que objetivam ampliar a inserção dos usuários na gestão do hospital, isto é, o controle social, foram os seguintes:

1. a manutenção e fortalecimento do CONSELHO LOCAL DE SAÚDE (formado por usuários, profissionais e gestores do hospital)

2. a criação da OUVIDORIA (espaço institucional onde os usuários podem levar suas reclamações sobre o atendimento, além de sugestões para melhoria)

3. o PROJETO FAMILIARES PARTICIPANTES (espaço nas enfermarias, onde os pacientes e seus acompanhantes conversam sobre suas angústias, trocam experiências e também podem ter suas dúvidas esclarecidas pelos profissionais de saúde).

Esta riqueza e este refinamento dos dispositivos propostos, assim como o compromisso da sua direção com a qualificação do SUS, fizeram com que este hospital se tornasse um objeto de interesse de nosso estudo. Ele é um hospital geral, mas que tem o atendimento das urgências e emergências como prioridade. Possui 197 leitos, sendo 20 leitos de UTI, dois prontossocorro (adulto e infantil) e um ambulatório de espe- cialidades que presta atendimento aos egressos do Hospital e encaminhados da rede pública municipal de saúde. Possui um programa de residências médicas, reconhecido pelo MEC (coordenado pela Comissão de Residência Médica, COREME) e é campo de estágio para universitários de fisioterapia e para escolas de enfermagem sendo, portanto, um hospital de ensino.

O objetivo do presente trabalho é o de fazer uma análise de como tais dispositivos propostos pela diretoria têm causado impacto na micropolítica do hospital, em particular no modo de se fazer a gestão cotidiana do cuidado. Trabalhamos com a hipótese inicial - a partir de nossa experiência anterior com a condução de projetos semelhantes (Cecílio, 1997) - de que os trabalhadores, com seus interesses e com suas práticas, vão constituindo múltiplos campos de relações de força que "deformam" os vetores das diretrizes da direção, de forma que os dispositivos pensados para a implementação de tais diretrizes são reinterpretados, reapropriados com novos sentidos, quase sempre em consonância com antigas práticas e valores já bem estabelecidos. Dito de outra forma: as propostas de mudança que partem da direção são capturadas por instituídos organizacionais com muita força de reprodução.

\section{Metodologia do Estudo}

A metodologia do estudo consistiu em uma vivência no cotidiano de unidades assistenciais do hospital, visando a observação da rede de relações que se estabelecem entre os vários atores para a concretização do cuidado e, também, a caracterização de como os dispositivos de gestão da atual direção são apropriados pelos trabalhadores. As observações foram realizadas por uma residente do terceiro ano da residência em Medicina Preventiva e Social da Faculdade de Ciências Médicas da Unicamp, durante o período de 11 meses, no correr de 2003, e concentraram-se em alguns dos dispositivos ligados à gestão e à organização do processo de trabalho. Alguns dispositivos não foram objeto de investigação, em particular aqueles referentes ao controle social e, na organização do processo de trabalho, a sistemática de classificação de urgências no Pronto Socorro. Neste período foram freqüentadas algumas unidades assistenciais do hospital, buscando-se criar intimidade com o processo de trabalho realizado pelos trabalhadores e residentes, 
no seu dia-a-dia. 0 que se pretendia era caracterizar as relações que se estabelecem entre os profissionais de saúde no cotidiano do hospital e entre os vários setores do hospital para se garantir a oferta do cuidado aos usuários. Foram realizadas, também, entrevistas semi-estruturadas com alguns trabalhadores e gerentes das unidades trabalhadas. Foi adotado, ainda, um diário de campo para registro de fatos do cotidiano, em particular dos "ruídos" que iam sendo observados durante a vivência na unidade. Como foco inicial do estudo foi escolhida a enfermaria de cirurgia geral e de especialidades, por ser um espaço estratégico de observação do poder médico, além de ser coordenada por uma enfermeira. Em seguida, a observação foi realizada no centro cirúrgico, pela sua importante intersecção com esta enfermaria.

Através da vivência em duas unidades assistenciais, foi possível obter informações sobre o funcionamento do cotidiano do hospital, compreender os processos de trabalho que aí se desenrolam, o modo como os projetos da direção do hospital estão sendo implementados, as percepções que os profissionais da ponta têm de tal projetos e as dificuldades para sua real implementação.

As observações foram realizadas de acordo com as recomendações de "abordagem organizacional da ação social”, tal como feitas por Friedberg (1993). Através desta metodologia, prioriza-se a descoberta do terreno e da sua estruturação e o desenvolvimento de modelos descritivos e interpretativos que se ajustam ao terreno, além da vivência dos atores do campo para, a partir do que foi recolhido pelo analista, ele possa estabelecer uma relação de intersubjetividade com estes atores e possa promover uma análise de como o "constrangimento específico que as modalidades e as regras do jogo, através das quais um conjunto de atores estrutura a sua cooperação, fazem pesar sobre a capacidade de ação, de desenvolvimento e de mudança de cada um deles e do conjunto que eles formam" (Friedberg, 1993, p.30o). Com o intuito de estabelecer uma relação de empatia com os atores do campo, é necessário que o analista assuma uma postura menos crítica e mais indutiva, buscando obter os pontos de vista dos atores e considerando igualmente importantes todos os testemunhos, relatórios, entrevistas e fontes de dados. Durante sua fase de campo, o analista é comparado a uma esponja, por Friedberg, onde ele “não tem opinião, não tem idéias, mas é de uma curiosidade insaciável por tudo o que se passa no espaço de ação que lhe interessa. Toma nota de todas s indicações que lhe são fornecidas, segue os entrevistados no mais íntimo da sua 'subjetividade', ou seja, das suas argumentações, das suas justificações e das suas descrições, sem as contradizer, sem as reduzir nem as desqualificar, sem mesmo lhes opor o ponto de vista de um outro ator do campo" (Friedberg, 1993, p.306). Utilizamos, também, na formatação da metodologia, o trabalho referencial de Graça Carapinheiro (1998), em particular as sugestões de como realizar as observações cotidianas do hospital.

Como preparação para o trabalho de campo, foi feita uma revisão cuidadosa de todos os documentos oficiais que contêm tanto as diretrizes políticas mais gerais da direção, bem como de todos os dispositivos de gestão propostos para se melhor a gestão do hospital estudado.

\section{Construindo um Referencial Teórico para a Investigação}

Reconhecendo a inexistência de uma teoria "unificada" das organizações de saúde, dentre elas o hospital, temos advogado uma postura eclética na busca de autores e abordagens teóricas que, usados com certa liberdade e em diálogo entre si, nos permitam iluminar diferentes ângulos da vida da organização hospitalar. Essa tem sido, também, a opção de autores que, como Carapinheiro (1998), se propõem a construir uma sociologia das organizações hospitalares.

Tomamos, como ponto de partida das nossas reflexões, tanto os limites da teoria burocrática weberiana para o estudo do hospital (Carapinheiro, 1998), como a insuficiência do paradigma estrutural-funcionalista, cuja expressão síntese são as formulações de Talcott Parsons (Lins, 2004), para dar conta da complexidade do conjunto das relações que se estabelecem no hospital. Carapinheiro faz uma cuidadosa revisão da bibliografia para mostrar os limites do clássico modelo da burocracia, tal como definido por Max Weber. Para a autora, haveria no hospital um sistema dual de autoridade. De um lado, a autoridade do tipo legal-formal, topo-base, que permite explicar parte do funcionamento do hospital, em particular a gestão das áreas de apoio técnico e administrativo; do outro, a 
autoridade dos médicos, do tipo carismático, segundo a autora, o que resultaria em fluxos de autoridade transversalizados que cruzam, em todas as direções e sentidos, a vida da organização. Essa transversalização da autoridade médica e os fortes componentes de autonomia, ainda presentes em sua prática cotidiana, são o ponto de partida para a discussão da singularidade das organizações hospitalares. Por outro lado, as características mais marcantes do paradigma estrutural-funcionalista poderiam ser assim sintetizadas: a ausência formal de conflitos de interesse entre os sujeitos, uma vez que os interesses "da sociedade" são introjetados pelos indivíduos, levando-os a buscar a integração social; essa introjeção das normas justifica a busca pelo consenso e a concepção da organização/sociedade como sistema que tende à homeostase; as divergências são caracterizadas como disfunções a serem incorporadas pelo sistema, o que justifica a concepção da regularidade social e, finalmente, a presença da disciplina e do controle como eixo central dos métodos de gestão, aderindo, assim, a racionalidade gerencial hegemônica (Campos, 2000; Lins, 2004). Características parecidas são apontadas por Friedberg (1993) naquilo que ele denomina de "visão clássica das organizações”: o caráter racional e instrumental da organização em relação a fins exógenos, pré-determinados e fixos, aos serviços dos quais ela é uma simples correia de transmissão transparente, passiva e obediente; a idéia da coesão interna dos trabalhadores e sua adesão a um projeto "maior" da organização e a nítida separação entre o "interno" e o "externo", sendo que o "externo" invadiria ou penetraria a organização via mediações da direção superior. Apesar da existência de um esforço de superação de tais concepções para os estudos das organizações de saúde e seus processos de gestão, elas ainda conservam muita força explicativa nos estudos produzidos pela academia (Lins, 2004).

Para construirmos um painel teórico alternativo aos paradigmas burocrático e estrutural-funcionalista, bem como à concepção clássica da organização, temos incorporado reflexões feitas a partir de outros referenciais, em particular as contribuições da teoria da ação, de base sociológica, tanto na sua vertente mais fenomenológica, como nas reflexões mais contemporâneas do campo que se poderia denominar de estruturacionismo; a reflexão sobre as múltiplas di- mensões do poder existentes na vida hospitalar e a crítica aos teóricos das organizações, a partir das contribuições da sócio- análise, em particular os trabalhos já clássicos de Lourau (1995), Lapassade (1989) e Lourau e Lapassade (1972).

A relação entre o controle e a autonomia, determinação e liberdade, reprodução e criatividade permanece como tema ainda central da sociologia contemporânea (Domingues, 2001). Tal temática, quando pensada em relação aos trabalhadores do hospital, assume importância para se superar o paradigma estruturalfuncionalista ainda hegemônico no campo da saúde, como apontamos anteriormente. Para tratar disso, temos nos apropriado tanto da produção teórica que vem do campo da sociologia de base fenomenológica, inspirada na obra de Schutz (1979), em particular os trabalhos de Silverman (1975), Berger (1973) e Berger e Luckmann (1973), bem como dos autores da sociologia contemporânea que tratam da relação entre estrutura e liberdade, em particular os trabalhos de Bourdieu, entre outros, na síntese feita por Ortiz (1983), Giddens (2003) e Friedberg (1993). No caso dos primeiros autores, a ênfase é na liberdade humana, no caráter contingencial das organizações, construída e mantida pela ação humana. No segundo grupo de autores, o foco é no esclarecimento da relação entre a ação humana criativa e os constrangimentos estruturais, em particular a ênfase que dão ao duplo papel das "estruturas" de constrangimento e restrição, mas, ao mesmo tempo, oportunidade. Uma relação dialética entre determinação e liberdade, como aponta Campos (2000). O que há de comum nesses dois grupos é, afinal, uma maior ênfase à ação criativa dos atores institucionais que, sempre contornam, em alguma medida, as restrições e regras, reconstruindo, permanentemente e de forma ativa, as relações dentro das organizações.

Temos adotado essa visão que privilegia a criatividade, o inesgotável papel de articulação e mobilização de recursos por parte dos trabalhadores do hospital, de forma a construírem e reconstruírem arranjos que escapam, sempre, às linhas formais de autoridade. Por essa concepção, os trabalhadores são ativos na reinterpretação das diretrizes e dos objetivos organizacionais, de forma que poderíamos dizer que os trabalhadores do hospital são "produtores de texto" e não uma folha em branco, na qual a direção imprimiria, de forma não problemática seu próprio texto (seu projeto). 
Entendemos que vem desse campo uma das mais importantes contribuições para se colocar em cheque o paradigma estrutural-funcionalista.

Além das contribuições da teoria da ação, temos trabalhado com a idéia de que é possível identificar, nas organizações hospitalares, três dimensões de poder, distintas porém imanentes entre si: uma dimensão de autoridade/ordem, uma dimensão de disciplinamento/controle e uma dimensão de cooperação/ consenso (Moreira, 2002). A dimensão mais visível ou facilmente reconhecível das relações de poder existentes em uma organização é aquela que se expressa nos arranjos hierarquizados de autoridade, do tipo legalformal, tal qual formulado por Max Weber (1991) ao trabalhar o conceito de burocracia. Essa dimensão do poder, a da autoridade e ordem, se materializa nos organogramas formais, nos regulamentos, nos rituais do cargo e que tem como característica principal o fato da relação de dominação ser reconhecida como legítima pelos dominados. Estamos utilizando dominação no mesmo sentido empregado por Weber (1991) para quem "poder" seria uma categoria sociologicamente amorfa, preferindo pois utilizar o conceito de dominação. "Dominação é a probabilidade de encontrar obediência a uma ordem de determinado conteúdo, entre determinadas pessoas indicáveis" (p. 33).

Essa dimensão do poder/dominação, apesar de ser a mais facilmente reconhecida pelo senso comum, ao portar com ela o conceito de "chefe", não é suficiente para se pensar o conjunto das relações de poder que existem na organização hospitalar. Reconhecemos, então, uma segunda dimensão de poder na vida organizacional que é a dimensão que designamos de controle e disciplinamento. Essa é uma face do poder organização que não se expressa tão explicitamente nos organogramas formais, mas atravessa a organização como um todo e em todas as direções, não mais no sentido topo-base próprio da dimensão autoridade ordem. A produção teórica de Michel Foucault é a que mais tem contribuído para a reflexão sobre essa dimensão do poder organizacional. "As relações de poder se enraízam no conjunto da rede social. Isto não significa, contudo, que haja um princípio de poder, primeiro e fundamental, que domina até o menor elemento da sociedade; mas que há, a partir desta possibilidade de ação sobre a ação dos outros (que é co-extensiva a toda relação social), múltiplas formas de dispa- ridade individual, de objetivos, de determinada aplicação do poder sobre nós mesmos e sobre os outros, de institucionalização mais ou menos setorial ou global, organização mais ou menos refletida, que definem forma diferentes de poder" (Foucault, 1995, p.247). Ainda Foucault, falando sobre as múltiplas formas de dominação que podem exercer na sociedade, faz a seguinte afirmação que esclarece sobremaneira o referencial que temos adotado em nossas observações, "portanto, não o rei em sua posição central, mas os súditos em suas relações recíprocas: não a soberania em seu edifício único, mas as múltiplas sujeições que existem e funcionam no interior do corpo social. Logo, não se trata de analisar as formas regulamentares e legítimas do poder em seu centro, no que possam ser seus mecanismos gerais e seus efeitos constantes. Trata-se de captar o poder em suas extremidades, em suas últimas ramificações, lá onde ele se torna capilar; captar o poder nas suas formas e instituições mais regionais e locais" (Foucault, 2003, p.181-2). É com esta compreensão que este trabalho buscou debruçar-se sobre a organização dos processos de trabalho das unidades assistenciais, aproximando-se dos profissionais de saúde e analisando a sua tradução na prática do projeto da diretoria atual.

Carapinheiro (1998), a partir do conceito de sociedades disciplinares desenvolvido por Foucault, aponta a dimensão disciplinamento existente no hospital, ao destacar que há todo um fluxo de registros desde a identificação do paciente na sua chegada ao hospital e a disposição e enumeração dos leitos, até informações sobre o ato cirúrgico, horários, motivo da cirurgia, motivo do cancelamento, equipe presente, fluxo do paciente após a cirurgia, se houve óbito ou cura, anotação do todos os materiais utilizados no ato cirúrgico, exames solicitados, receitas médicas. Constitui-se, assim, um campo documental no interior do hospital que não é somente um lugar de cura, mas também de registro, acúmulo e formação de saber. A disciplinarização dos atos hospitalares. Por outro lado, a construção de organizações hospitalares cada vez mais panópticas (Foucault, 200o), através da informatização de todos os recantos e atividades do hospital, somada a todos os processos de acreditação e demais programas de pontuação e classificação dos hospitais, além da protocolização crescente e uso intensivo de indicadores e incontáveis mecanismos de 
prestação de contas; enfim, tudo o que aponta no sentido de normalizar e avaliar todos os aspectos da vida hospitalar, de capturar de todas as formas possíveis os espaços de autonomia dos trabalhadores, em particular dos médicos, são, na nossa opinião, um poderoso movimento de aumento de controle na vida hospitalar.

Ainda a partir das idéias de Foucault, temos adotado a imagem de uma rede para pensar as relações de poder no hospital. "O poder não é algo que se possa dividir entre aqueles que o possuem e o detêm exclusivamente e aqueles que não o possuem e são submetidos. 0 poder deve ser analisado como algo que circula, ou melhor, como algo que só funciona em cadeia. $\mathrm{O}$ poder funciona e se exerce em rede. Nas suas malhas os indivíduos não só circulam, mas estão sempre em posição de exercer este poder e de sofrer sua ação; nunca são o alvo inerte e consentido do poder, são sempre centros de transmissão"(Foucault, 2003, pg 183). Como metáfora de tal concepção de poder em rede, temos nos utilizado da imagem da aranha que, ao mesmo tempo que secreta, ativamente, os fios que tecem a rede, fica presa às possibilidades e aos caminhos que estão contidos na rede que teceu. Disciplinamento e controle, portanto, como uma dimensão do poder na vida organizacional que, para além das linhas de autoridade legal-formal impressas nos organogramas formais, falam-nos de inumeráveis relações que formigam na micropolitica do hospital e que precisam ser levadas em conta no desafiador processo de gestão das organizações hospitalares.

Mas há, ainda, uma terceira dimensão do poder nos hospitais e que estamos denominando de cooperação/consenso. Por essa dimensão, está-se mais atento à idéia de poder de, do que poder sobre (presente nas duas dimensões anteriores) (Lukes, 1970). Podemos encontrar indicações para pensarmos tal dimensão do poder em autores tão diferentes como Hannah Arendt e Talcott Parsons. Arendt (2001), criticando “a convicção de que o tema político mais crucial é, e sempre foi, quem domina quem", afirma que "o poder corresponde à habilidade humana não apenas para agir, mas para agir em concerto. $O$ poder nunca é propriedade de um indivíduo, pertence a um grupo e permanece em existência apenas na medida em que o grupo conserva-se unido" (p.36). Ou ainda, "o poder emerge onde quer que as pessoas se unam e ajam em concerto, mas sua legitimidade deriva mais do estar junto inicial do que qualquer ação que possa seguirse" (p.4o). Para Parsons (apud Lukes, 1980), por sua vez, "o poder, então, é a generalizada capacidade de assegurar o desempenho de obrigações por parte de unidades, num sistema de organização coletiva, quando as obrigações são legitimadas com referência ao seu impacto sobre metas coletivas e onde, no caso de recalcitrância, há um pressuposto de imposição de sanções de qualquer que seja a real agência daquela imposição". Ou seja, para Parsons, "a conceituação de poder liga-se à autoridade e busca de metas coletivas, e desassocia-se dos conflitos de interesse e, em particular da coerção e força" (Lukes, 1980, p.24). A visão parsoniana de poder é hegemônica na produção teórica sobre as organizações que denominamos de estrutural-funcionalista, com sua ênfase nas organizações como "sistemas cooperativos" (Barnard, 1971). Já a concepção arendtiana pode ser identificada em autores que advogam a possibilidade de construção de novos consensos, no interior de colegiados organizacionais, como pressuposto fundamental para a mudança organizacional (Cecílio, 1997; Campos, 200o). De qualquer forma, reiteramos nossa opinião de que as três dimensões do poder apresentadas, construídas a partir de referenciais teóricos tão diferentes, estão presentes, de forma imanente, em todas as organizações, e nas hospitalares em particular, e levá-las em conta em suas especificidades constitui-se em um dos maiores desafios para a função gerencial. Freqüentemente, modelos de gestão do tipo participativo, mais "democrático", que enfatizam a dimensão cooperação/ consenso, deixam na sombra as outras dimensões do poder, o que pode explicar um certo "mal estar da organização", isso é, os trabalhadores são de alguma forma subestimados na sua capacidade de percepção das contradições entre os vários tipos de sentidos da vida organizacional sinalizados pela direção, e operacionalizados, em particular, pelas gerências que lhe são mais próximas. Usando uma imagem que vem do senso comum, e cantada pela Rita Lee em uma de suas músicas, poderíamos dizer que "a mão que afaga é a mão que afoga”. Esse paradoxo está inexoravelmente presente na função gerencial: bater, disciplinar, controlar, vigiar e punir, mas também afagar, convocar para a cooperação, exercer a sedução e o agir comunicativo, para a construção de fugazes consensos em torno de convocatórias para a ação, em torno dos “obje- 
tivos organizacionais”. Alinhamento de vetores dissonantes em relação ao grande vetor da macroracionalidade organizacional. Rozendo (200o), de alguma forma, tematiza esta preocupação/contradição ao defender a necessidade de se buscar, no conceito de poder construído por Hannah Arendt, embasamento para uma nova prática da enfermagem pautada por uma postura de liderança, a partir da competência de se fazer a convocatória para ação de sujeitos "em concerto”, muito mais do que partir da utilização da violência e da banalização da enfermagem no mundo do trabalho, aspectos estes típicos das atuais práticas gerenciais. A nossa indagação é sobre o quanto se trata de fazer um movimento "substitutivo" de uma prática da violência, do exercício da autoridade visando a construção e manutenção de uma determinada "ordem organizacional” por uma prática mais concertada, consensuada, ou, se, inapelavelmente, teremos que conviver com o exercício das três dimensões na função gerencial e, mais do que isso, fazer, dessa tensa convivência, matéria prima para a gestão.

Por fim, temos incorporado a crítica sobre a teoria das organizações formulada pelos autores da sócio-análise francesa, em particular nos trabalhos de George Lapassade (1989), René Lourau (1995) Lapassade e Lourau (1972). A partir de assumida filiação à dialética hegeliana, os autores trabalham com a idéia da existência de três momentos na vida social. 0 momento da universalidade, representado pelos sistemas de normas, os valores que orientam a socialização, a ideologia, o instituído, enfim; o momento da particularidade (negação do anterior), cujo conteúdo se resume às determinações materiais e sociais que negam a universalidade dada no primeiro, ou o instituinte; o momento de singularidade (negação da negação) onde o conceito de instituição tem por conteúdo as formas organizacionais, jurídicas ou anônimas necessárias para atingir determinado objetivo ou determinada finalidade, é o momento da institucionalização. Lapassade e Lourau afirmam que os sociólogos idealistas e os marxistas ortodoxos detêm-se no primeiro momento do conceito, focando o sistema de normas; os subjetivistas isolam-se no segundo momento, caindo na ideologia das necessidades interiorizadas como a base da socialização e que a sociologia das organizações autonomiza o terceiro momento, dando ênfase à racionalidade e positividade das formas sociais em detri- mento da história, das contradições e da luta de classes. 0 papel da análise institucional seria o de mostrar os funcionamentos divergentes, contraditórios e anta gônicos presentes nos momentos de negação de cada um deles (Lins, 2004).

Temos consciência de que o diálogo entre autores tão diferentes não é simples e não pode ser "resolvido" com alguma espécie de síntese, por certo impossível. Ele permanecerá sempre em aberto, ora iluminando mais certas dimensões da vida organizacional, ora outros. É como se, diante da riqueza das relações que se estabelecem na micropolítica do hospital, ora ficassem mais evidentes os traços de liberdade e criatividade aparentemente quase ilimitados por parte dos trabalhadores, ora se destacassem mais os aspectos de determinação, captura e reprodução de certas relações instituídas. Observados sob certos ângulos, os hospitais são todos muito parecidos entre si; ao mesmo tempo, cada organização hospitalar pode ser percebida na sua singularidade, fruto da construção e reconstrução permanente de fluxos, relações, enfrentamentos, composições, que se apresentam como um caleidoscópio de possibilidades e de desenhos que nos parecem quase irracionais ou caóticos, principalmente se insistimos em "enquadrá-los" sob uma única racionalidade. Uma ilusória macroracionalidade organizacional, que os dirigentes pensam encarnar e ser a única, é, de fato, apenas uma das incontáveis racionalidades presentes no hospital. Uma macroracionalidade organizacional que poderia ser pensada como um vetor resultante da combinação de uma certa ética de convicção (referente a valores, visão do mundo), no sentido weberiano do termo, com sua ética de responsabilidade correspondente (do tipo instrumental, de adequação de meios a fins) (Saint Pierre, 1993). Tanto a visão clássica das organizações, como o paradigma estrutural-funcionalista, seu quase sinônimo, pensam ou trabalham com o pressuposto de que essa pretendida macroracionalidade organizacional, seja única. Desconhecem que a organização hospitalar é um território extremamente complexo, justamente pelo entrecruzamento de múltiplas, incontáveis racionalidades, compostas, elas próprias, por outras tantas éticas de convicção e de responsabilidade. Pensamos, então, que o referencial teórico intencionalmente eclético que temos adotado, tem o mérito de permitir nos essa liberdade de lidar, de forma elástica, com os múltiplos 
sentidos que assumem as relações entre os atores que constroem as organizações hospitalares. É a partir dele e com ele que tentamos refletir sobre as observações empíricas desse trabalho que apresentamos a seguir.

\section{Uma Reflexão sobre as Nossas Obser- vações}

Nesta etapa do artigo, temos a pretensão de discorrer sobre as observações realizadas durante o ano de 2003 do referido hospital, buscando retomar nossa hipótese inicial de trabalho, qual seja, a de que os trabalhadores, com seus interesses e com sua prática, vão constituindo múltiplos campos de relações de força que "deformam" os vetores das diretrizes da direção, de forma que os dispositivos pensados para a implementação de tais diretrizes são reinterpretados, reapropriados com novos sentidos, quase sempre em consonância com antigas práticas e valores já bem estabelecidos. Nas nossas observações, pudemos verificar que a realidade se mostra muito mais complexa do que as normas estabelecidas pela direção. 0 cotidiano do hospital encontra-se atravessado por regras formais e informais que, todo o tempo, influenciam e modificam o projeto de gestão da atual administração. Os novos dispositivos não conseguem ser implementados plenamente no dia-a-dia do hospital, pois a lógica da direção estabelece-se como apenas uma das lógicas que irão influenciar na definição das ações realizadas pelas profissionais de saúde.

Quando nos deparamos com o organograma real que rege, de fato, o cotidiano do hospital, vimos que, apesar da direção ter se debruçado na construção e implementação de uma nova proposta de organização dos espaços de gestão e de novos cargos de coordenação, buscando desenvolver a gestão democrática e participativa através de sistemas de co-gestão para promover a distribuição do poder, as corporações profissionais impõem-se para proteger seus territórios de saber-poder, construídos durante os longos anos da história do hospital e das profissões, principalmente a médica. Pudemos verificar isso quando as referências técnicas (como o próprio nome já diz, deveria se responsabilizar apenas pela orientação técnica, sem relação hierárquica com os trabalhadores) mantêm seu poder de definir a organização das escalas de trabalho, as férias e saídas para congressos e outros espaços científicos, sob o aval da coordenação da unidade assistencial.

Apesar de uma nova organização da gerência das unidades assistenciais, onde há a coordenação gerencial e o gerente, o poder gerencial está diluído entre as chefias das corporações e os médicos e outros profissionais, os quais mantêm sua autonomia na decisão das férias, folgas, freqüência e plantões, além, é claro, de todas as decisões relativas à organização do processo de trabalho. Apesar da proposta de mudança, o hospital mantém a característica dos hospitais, onde o poder está nas "bases" ou nas áreas assistenciais e ocorre uma forte fragmentação das linhas formais de mando entre as várias categorias profissionais, sendo que as várias corporações organizam-se segundo lógicas bem próprias. "Os médicos mantêm uma relação de autonomia em relação à organização; o gerente não 'manda' formalmente nos médicos, mas atua através de acordos e entendimentos, regidos por uma certa ética profissional corporativa e um acentuado espírito de corpo; ele é muito mais um representante dos interesses dos médicos diante da administração do que o contrário; o corpo médico funciona como cliente do hospital, no sentido de que vê tanto a enfermagem, como o corpo administrativo no papel de 'fornecedores' de insumos para seu trabalho. A enfermagem constitui um corpo profissional muito fechado em si, também autônomo em relação à direção; há uma linha de mando vertical formalizada e legitimada; ela gerencia o cotidiano do hospital e assume a gerência efetiva das unidades assistenciais, embora haja conflito com o poder médico. 0 corpo administrativo é o mais silencioso dentro do hospital, embora detenha recursos estratégicos para a gestão do cotidiano; é a área mais estruturada com normas e rotinas estabelecidas; ele também apresenta linha de mando vertical formalizada e legitimada" (Cecílio e Merhy, 2003).

Também percebemos que a instituição de colegiados de gestão não garante, por si só, a distribuição de poder e o estabelecimdento de espaços de decisão legitimados por todos os profissionais de saúde. As propostas definidas nos COLEGIADOS GESTORES DAS UNIDADES não são incorporadas pela maioria dos trabalhadores, por, aparentemente, não se sentirem e nem se fazerem representados neste espaço. Há uma 
baixa participação dos trabalhadores nesses espaços, em particular dos médicos, quase sempre ausentes ou silenciosos quando presentes. Além disso, o COLEGIADO GESTOR DO HOSPITAL, desprovido de poder decisório real, acaba tornando-se um órgão mais consultivo e menos deliberativo. As intervenções ficam restritas a algumas pessoas mais propositivas, principalmente àquelas que compõem o NÚCLEO EXECUTIVO, onde são tomadas as decisões gerenciais mais substantivas para o hospital. Portanto, os espaços onde deveriam acontecer a co-gestão e a distribuição de poder, mantêm-se como lugares onde poucos decidem por muitos.

Observamos que os coordenadores gerenciais e os gerentes das unidades assistenciais assumem, na maior parte do tempo, a solução de problemas de gerenciamento do cotidiano, quer dizer, "apagando incêndios diários”, do que com o planejamento e o monitoramento das ações para a qualificação do atendimento na unidade sob sua responsabilidade. Como já comentado anteriormente, os colegiados das unidades, esvaziados, não permitem que as propostas aí surgidas tenham eco para todos os trabalhadores do setor. A partir da nossa participação em reuniões do colegiado gestor da unidade assistencial, pudemos observar que os médicos não participam da pauta que se refere à gerência do cuidado e às questões relativas ao cotidiano das enfermarias. Os médicos, poucos presentes, discutem a questão referente à ocupação dos leitos e criticam a atual gestão no que tange a rapidez das mudanças ("não há tempo suficiente para a incorporação das mesmas”). Poucos auxiliares de enfermagem participam, sendo o espaço monopolizado pelas enfermeiras e pelo tema do gerenciamento do cotidiano do hospital. A baixa adesão dos trabalhadores às reuniões do Colegiado pode significar uma resistência pacífica e boicote a esta proposta da direção. "Determinado modo de se pensar a gestão dos serviços de saúde, em particular do hospital, de recorte democrático, descentralizado, com ênfase na autonomia, direção colegiada em todos os níveis da organização é, paradoxalmente, visto como controlista por essses mesmos trabalhadores, para quem se supunha estar garantindo uma maior participação da gestão" (Cecílio, 1999, p.316). Cecilio, em relatório de avaliação de quatro anos de implantação do modelo de gestão descentralizado e participativo no Hospital São João da Boa Vista de Volta Redonda (RJ), 1998, afirma. "O rela- tório, se por um lado confirma as já conhecidas estratégias de não-adesão dos médicos a qualquer modelo que tenha alguma veleidade de controlista, por outro, aponta como as enfermeiras desenvolvem estratégias competentes de ocupar e hegemonizar novos dispositivos institucionais pensados para democratizar a vida da organização, inclusive como forma de se fortalecerem perante os médicos e vários movimentos de deslocamento e reconcentração de poder em instâncias pensadas como dispositivos para democratização da vida institucional" (Cecílio,1999, p.317).

O modo como os colegiados têm sido efetivados vai ao encontro da afirmação de autores como Moreira, quando afirma que "mesmo os modelos participativos podem ser altamente controladores, seja pela falta de legitimidade das decisões, quando o grupo funciona apenas como referendo, ou pela maior visibilidade que se consegue sobre as práticas dos trabalhadores" (Moreira, 2002, p.223).

Também vimos, nos colegiados gestores das unidades, relatos de servidores que transmitem a angústia de que os pedidos feitos à administração, para que as propostas de mudanças deliberadas nestes espaços sejam implementadas, na maioria das vezes não são atendidas, em geral, devido ao engessamento da estrutura burocrática hospitalar, fato este que deslegitima estes colegiados como espaço efetivo de deliberação.

Em relação às estratégias da direção para qualificar a atenção à saúde e ampliar o compartilhamento entre os profissionais de saúde, percebemos que elas não conseguiram quebrar a subordinação das decisões das demais profissões de saúde em relação às decisões médicas. Carapinheiro traz como reflexão o quanto "a autonomia médica é sustentada pela dominação do seu saber e de sua competência técnica na organização da divisão do trabalho e, como conseqüência, dirige e avalia o trabalho de todas as restantes categorias profissionais sem, em contrapartida, ser objeto de direção e avaliação de ninguém" (p. 53-54). 0 dispositivo prontuário integrado tornou-se um espaço comum para anotações das diferentes profissões, sem estabelecer, de fato, o diálogo entre elas. A estratégia de instituir equipes de referência não foi de fato estabelecida, tendo como demonstração disto o fato dos auxiliares de enfermagem não aceitarem permanecer cuidadores de um mesmo leito, justificando tal postura pela sobrecarga de trabalho de uns em relação a 
outros. Também não foram instituídas reuniões multiprofissionais para a discussão dos casos; apesar de estar estabelecida a visita geral, na prática, as discussões nos leitos se limitam aos saberes médicos, definidores do poder médico, o que inibe a participação de outros saberes de cuidado, além do cuidado médico. Os demais profissionais reagem através da não participação ou do silêncio. Também não há inclusão dos pacientes na discussão sobre si mesmos, nem questionamento das suas necessidades além da assistência médica.

O acompanhamento médico dos pacientes na enfermaria de cirurgia é feito de forma referenciada pelos residentes, que são orientados por médicos nem sempre com inserção diária na enfermaria. Os cirurgiões se organizaram por áreas de afinidades e cada grupo de médicos se responsabiliza por todos os pacientes da sua área. Eles, médicos e residentes, também têm uma inserção em todas as unidades assistenciais (pronto-socorro, ambulatório, centro cirúrgico e enfermaria), o que permite um acompanhamento mais próximo do paciente em toda a sua linha de cuidado. Não há um compartilhamento das decisões com os demais profissionais de saúde das unidades assistenciais, sendo esta uma organização especificamente médica. São, as enfermeiras, as verdadeiras tecedoras de relações entre os diferentes profissionais e entre as diferentes unidades assistenciais para assegurar o cuidado integral dos pacientes, apesar delas estarem fixas na unidade assistencial e não percorrerem, como os médicos, a linha de cuidado dos pacientes. Elas são as verdadeiras gerentes do cuidado ao paciente, orquestrando o processo de trabalho da equipe de enfermagem e estabelecendo relações com as unidades de produção como farmácia, almoxarifado, lavanderia, esterilização, entre outros, para garantir os insumos e equipamentos necessários para evitar a “desassistência”. Elas têm também um papel fundamental na alta do paciente e nas orientações dos cuidados para o paciente e seus acompanhantes. Logo, o médico trabalha em uma lógica mais longitudinal em relação à linha de cuidado e a enfermagem em uma lógica mais focal. São lógicas complementares e que necessitam de intenso processo de negociação e conversação entre as duas categorias profissionais para que esta complementariedade aconteça de forma plena. Porém, na prática, a enfermagem não detém o poder formal para tomar as todas as decisões necessári- as devido ao atravessamento da dominação médica. Também é essencial destacar como os médicos (incluindo os residentes) controlam o recurso crucial de assistência, ou seja, a definição do acesso ao leito, o que mostra o seu lugar estratégico de poder dentro da organização hospitalar.

Qualquer um destes atos, de interferência ou de indiferença, traz à tona o poder médico e a sua indisponibilidade para relações horizontais com outros profissionais não-médicos. A dominação médica, como correspondendo a um conjunto de estratégias desenvolvidas para o controle da situação do trabalho, para a institucionalização da autonomia profissional na divisão de trabalho médico e para a ocupação de uma posição de soberania sobre as categorias profissionais que estão em sua órbita. "Há três modos de dominação: subordinação (das categorias profissionais que cooperam com os médicos na divisão do trabalho, como é o caso da enfermagem), limitação (através de processos de contenção e restrição dos domínios de ação profissional de grupos que não dispõem de conhecimentos de medicina, mas detém competências equivalentes), exclusão (determina a situação de marginalidade e ilegalidade de várias formas de produzir cuidados médicos que fazem aplicação de conhecimentos e procedimentos tradicionais e arcanos, rejeitados pelas ciências médicas)" (Carapinheiro, 1998, pg.72). Na nossa observação, por exemplo, o saber da fisioterapeuta, fundamental para o cuidado de pacientes em um hospital com o perfil do estudado, está subordinado ao saber médico. Suas opiniões são freqüentemente ignoradas pelos médicos, que insistem em manter uma posição de soberania dentro das unidades assistenciais.

Diante disto, ressalta-se o exercício coorporativo dos médicos, a conservação de sua autonomia profissional e social e o desenvolvimento de um corpo sistemático de conhecimentos científicos para o controle dos saberes dos pacientes e de outros profissionais não-médicos.

As relações entre médicos e não-médicos assumem um distanciamento hierárquico que confirma a "posição"que os médicos possuem dentro da organização (Cecilio e Merhy, 2003), fato bastante presente em nossa observação. "A autonomia médica é sustentada pela dominação do seu saber e de sua competência técnica na organização da divisão do trabalho e, como conse- 
qüência, dirige e avalia o trabalho de todas as restantes categorias profissionais sem, em contrapartida, ser objeto de direção e avaliação de ninguém. Na própria configuração organizativa, o hospital apresentase como um conjunto de várias oficinas de trabalho, entendidas como lugares onde vários tipos de trabalho, diferentes recursos e específicas divisões de trabalho são requeridos para levar a cabo o trabalho médico, orientado, direta ou indiretamente, para a gestão dos casos clínicos dos doentes, justificando a subordinação das profissões que cooperam com os médicos na divisão de seu trabalho" (Carapinheiro, 1998, p.72). Apesar disto, em algumas situações, os não-médicos desafiam o poder médico e definem ações tendo como prerrogativa o cuidado do paciente. Esta autonomia reflete a referência de Foucault à questão da liberdade dos atores como condição para a existência do poder e para o desenvolvimento de suas estratégias. Em Foucault, os sujeitos "livres" aparecem "dotados de um campo de possibilidades de condutas, reações e modos de comportamento, que os constituem, simultaneamente, como condição e alvo do exercício do poder, mas também como oposição e resistência aos excessos resultantes do seu exercício descontrolado" (Foucault apud Carapinheiro, 1998, p.77). Alguns grupos de médicos e enfermeiras organizaram protocolos, porém são restritos aos cuidados médicos e de enfermagem, respectivamente. Não existem protocolos para o cuidado integral e multiprofissional.

Encontramos, no cotidiano, situações em que os profissionais não-médicos desafiam a dominação médica, gerando tensão nas relações inter-profissionais. Porém não se percebe uma intenção, por parte deles, de reflexão sobre estes conflitos e modificação de sua prática, mas sim uma resistência em trabalharem cooperativamente.

No fogo cruzado das corporações, encontramos o paciente em uma situação de total dependência e submissão das decisões médicas e das regras definidoras dos cuidados realizados pela equipe de enfermagem, não participando dos espaços ou momentos de definições sobre o seu cuidado. Percebemos o movimento das assistentes sociais do hospital em criar espaços de interação da equipe com os pacientes e seus acompanhantes, mas há baixa adesão da equipe de saúde.

É perceptível o incômodo causado à equipe de enfermagem e médicos pelos pacientes que têm desejos, críticas e reclamações. Outro momento pouco aproveitado para se propiciar a participação do paciente em seu processo de cura é a visita geral, realizada na enfermaria de cirurgia geral. Ela limita-se à discussão dos quadros clínicos, centrada em saberes médicos, não acontecendo uma discussão centrada no cuidado integral ao paciente, com o compartilhamento dos diversos saberes, inclusive do paciente, na medida em que este ainda é considerado como objeto das intervenções da equipe e não sujeito.

Em se tratando de um hospital que se propõe a ser escola de residência médica, algumas considerações são necessárias sobre este tema. Na cirurgia, o residente está inserido na linha de cuidados dos pacientes cirúrgicos, desde sua chegada até a pós-alta, sendo eles responsabilizados pelos cuidados ao paciente. Porém, não se percebe uma preocupação na educação destes médicos no que se refere ao cuidado multidisciplinar e à uma forma mais participativa do paciente em seu próprio processo de cuidado. Mantém-se a multiplicação de uma postura médica de dominação sobre os demais profissionais e sobre o paciente.

\section{Conclusões}

Nossas observações, durante meses, em duas enfermarias muito importantes no hospital estudado, nos permitem reforçar a hipótese inicial de que as intenções de se implantar modelos gerenciais mais racionais e coordenados, visando a uma certa concentração dos trabalhadores em torno dos objetivos da direção - no nosso caso, a construção de um hospital de qualidade e integrado ao SUS - serão "deformadas" ao atravessarem denso campo de forças imanentes à micropolítica do hospital. Ali onde estão os trabalhadores, atuando no limite de suas possibilidades de autonomia, criam e recriam, de forma permanente e dinâmica, práticas, fluxos, relações, reconstruindo, sempre, em alguma medida, a "realidade organizacional". Mesmo presos às demarcações bastante rígidas que as instituições como a Medicina e a Burocracia estabelecem ao atravessarem as organizações e cada um dos seus grupos, reafirmando hierarquias de dominação entre as categorias profissionais construídas aquém do hospital, em particular o poder que o médico dispõe em relação aos demais trabalhadores, o que se pode observar é um ruidoso mundo onde inúmeros atores se movem, 
se comunicam, jogam, utilizam cada um dos seus recursos para defender espaços de autonomia, mesmo que sejam mínimos, para suas práticas cotidianas. Há uma fascinante e incessante busca de preservação de identidade, de defesa de interesses, de espaços de autonomia, mas também de "boas práticas" por parte dos trabalhadores, muito mais referenciadas aos seus valores individuais, à sua biografia, à sua ética de convicção ou sua visão de mundo e, em boa medida, às suas corporações, do que a um ordenamento racional que a direção pensa poder impor.

Há sempre uma incontornável distância entre as equipes envolvidas diretamente no cuidado e a direção do hospital, de forma que as diretrizes dessa última, sejam elas quais forem, são sempre reinterpretadas, reinventadas, digeridas e recriadas, antropofagicamente, pelos primeiras. Nesse sentido, o mundo racional e ordenado que a direção sempre busca ou quer enxergar, seja através de novos modos de se fazer a gestão, seja através de programas de qualificação das práticas hospitalares, acabam existindo, em boa medida, apenas em sua idealização e desejo. Pelo menos em sua formulação original. No hospital estudado, fica evidente como os objetivos e atribuições formulados nos documentos oficiais adquirem outras características e sentidos quando vistos na sua operacionalização concreta pelos gerentes.

Pensamos que, mais do que a "construção de sujeitos coletivos" - uma certa idealização de grupos com determinada "matriz discursiva" homogênea, de preferência coincidente com a da direção - o que se nota são espaços habitados por atores, sujeitos, que disputam projetos e interesses bastante diferenciados. Énesses espaços que se observa a reprodução da lógica das corporações e seus lugares institucionais de poderes.

O desafio, na nossa opinião, seria utilizar esses territórios, sempre tensos, como espaços de negociações, novas pactuações, sempre considerando a impossibilidade de criação de um discurso hegemônico e homogêneo com poder de anular as diferenças irredutíveis portadas pelos atores reais. A quase utopia seria, se tomamos como referência a hegemonia dos atuais métodos de gestão, construir uma prática gerencial radicalmente dialógica, isso é, calcada na busca incessante de práticas comunicativas entre a gerência e os trabalhadores, que conseguisse, no limite, tomar, como matéria para discussão e debate, os inevitáveis meca- nismos de autoridade, disciplinamento e controle, presentes na vida organizacional. Quem sabe uma possibilidade de se enfrentar, em algum grau, o mal-estar sempre presente na vida das organizações.

Apesar dos inúmeros arranjos institucionais adotados, em particular as instâncias de coordenação e co-gestão, que afinal de contas dão a impressão de serem excessivos no caso estudado, fica-se com a impressão que a coordenação do cotidiano, do cuidado direto ao paciente, passa, de fato, por mecanismos que não são exatamente o que a direção propôs. Apesar de tantas instâncias colegiadas pensadas como novos espaços de poder e decisão mais compartilhados, sempre presos à uma lógica afinal racionalizadora e controlista, que supõe ser possível tudo prever, acompanhar e avaliar, pensamos que o poder real da instituição está polarizado em duas pontas: de um lado, no "topo", no NÚCLEO EXECUTIVO, onde são tomadas as decisões mais importantes para o cotidiano do hospital e, de outro, na "base", nas equipes, dividido entre médicos e enfermeiros, com forte poder de melhor pensar estratégias envolvidas no cuidado direto ao paciente. Algo como se todos os arranjos de co-gestão interpostos entre esses dois pólos, em particular os colegiados das unidades e o de gerência, ficassem esvaziados do seu potencial de construir uma lógica mais descentralizada e compartilhada de poder na organização. Aos gerentes, não sobraria outro papel senão o de JANUS, a deusa grega de dupla face, ao terem que voltar seu olhar ora para os interesses da direção, e seus sentidos de concertação, controle, condução e desejo de governo, ora para os trabalhadores e seus fortes movimentos de autogovernos, mesmo que em campo previamente estruturados por bem marcadas relações de poder. Ao final, confirma-se a impressão de que não há gestão possível do hospital sem uma forte concentração do poder no topo da organização, onde ficam concentradas as decisões estratégicas do hospital. Por outro lado, evidencia-se, plenamente, a irredutível resistência dos autogovernos dos trabalhadores a qualquer pretensão macroracionalizadora da direção, bem como a necessidade de construção de modos de se fazer a gestão que se orientem para construção de um novo pacto ético-político no hospital, que tenha como referência e ponto de partida, sempre, o mundo do trabalho e as relações reais que estabelecem seus atores entre si e com os usuários. 


\section{Referências}

ARENDT, H.. Sobre a violência. . Rio de Janeiro, Relume Dumará. 2001. 114p.

BARNARD, C.. As funções do executivo. São Paulo: Editora Atlas. 1971. 322p.

BERGER, P. Perspectivas sociológicas: uma visão humanista. Petrópolis: Vozes. 1973. 202p.

BERGER, P; LUCKMANN, T.. A construção social da realidade: tratado de sociologia do conhecimento. Petrópolis: Vozes. 1973. 247p.

CAMPOS, G.W.S. Um método para análise e co-gestão de coletivos. São Paulo: HUCITEC. 2000. 236p.

CARAPINHEIRO, G. Saberes e poderes no hospital: uma sociologia dos serviços hospitalares. Porto: Edições Afrontamento. 1998. 295p.

CECÍLIO, L.C.O A modernização gerencial dos hospitais públicos: o difícil exercício da mudança. São Paulo: Rio de Janeiro, 31(3):36-47, maio/jun. 1997.

CECÍlLIO, L.C.O. Inventando a mudança na saúde. São Paulo: Hucitec. 1997. 333p.

CECÍLIO, L.C.O. Autonomia versus controle dos trabalhadores: a gestão do poder no hospital. Rio de Janeiro: Ciência \& Saúde Coletiva, 4(2):315-329. 1999

CECÍLIO, L.C.O; MERHY, E.E.. O singular processo de coordenação dos hospitais. Saúde em Debate, Rio de Janeiro, v. 27, n. 64, p. 110-122. 2003.

COSTA, N.R; RIBEIRO, J.M.; SILVA, P.L.B.. A experiência da reforma do setor saúde: inovações organizacionais e de financiamento. São Paulo: Revista de Administração Pública. 32(1):209-227. 2000

DOCUMENTO OFICIAL DO HOSPITAL. Manual do Sistema de Gestão. Mimeo, 2002.

DOMINGUES, J.M.. Teorias sociológicas no século XX. Rio de Janeiro: Civilização Brasileira. 2001. 110p.

FOUCAULT. M.. O sujeito e o poder, pp. 231-249. In: RABINOW P; DREYFUS, H. Michel Foucault, uma trajetória política: para além do estruturalismo e da hermenêutica. Rio de Janeiro: Forense Universitária. 1995. 299p.
FOUCAULT, M.. O panoptismo, pp 162-187. In: Vigiar e punir. Petrópolis: Editora Vozes. 2000. 262p.

FOUCAULT, M. Soberania e Disciplina In: Microfísica do Poder, $18^{\mathrm{a}}$ ed, Graal, Rio de Janeiro. 2003. 295p.

FRIEDBERG, E.. O poder e a regra: dinâmicas da ação organizada. Lisboa, Instituto Piaget.1993.412p.

GIDDENS, A. A constituição da sociedade. São Paulo: Martins Fontes. 2003. 458p.

LAPASSADE, G. e LOURAU, R.. Chaves de Sociologia. Rio de Janeiro: Editora Civilização Brasileira. 1972. 203p.

LAPASSADE, G.. Grupos, organizações e instituições. Rio de Janeiro: Francisco Alves. 1989.313p.

LOURAU, R.. A Análise Institucional. Petrópolis: Vozes. 1995. 291p.

LINS, A.M.. Produções teóricas na área de gestão e avaliação em saúde: o esforço de construção de um novo paradigma. Campinas, 2004. 25of. Tese (Doutorado em Saúde Coletiva) - Faculdade de Ciências Médicas, Universidade Estadual de Campinas.

LUKES, S.. O poder: uma visão radical. Brasília, DF: Editora Universidade de Brasília. 1980. 72p.

MALICK, A.M; TELES, J.P.. Hospitais e programas de qualidade no estado de São Paulo. São Paulo: Revista de Administração de Empresas, v.41:p. 51-59. 2001.

MERHY, E.E.. Saúde: a cartografia do trabalho vivo. São Paulo: Hucitec. 2002. 189p.

MOREIRA, M.E. Autoridade/Ordem, Disciplinamento/ Controle e Cooperação/Consenso: as dimensões imanentes do poder nas organizações -um estudo teórico para pensar a gestão em saúde. Campinas, 2002. 247f. Tese (doutorado em Saúde Coletiva) Faculdade de Ciências Médicas, Universidade Estadual de Campinas.

ORTIZ, R (org). Pierre Bourdieu: sociologia. São Paulo: Ática. 1983. 191p.

ROZENDO, C.A.. A liderança no cotidiano da enfermagem hospitalar: entre luzes e sombras. Ribeirão Preto, 2000. 229f. Tese (doutorado). Escola de Enfermagem de Ribeirão Preto, Universidade de São Paulo. 
SAINT-PIERRE, H.L.. Max Weber, entre a paixão e a razão. Campinas: Editora Unicamp, 3 a edição. Parte II: Do agir metódico à decisão valorativa. 1993.159p.

SCHIESARI, L.M.C. Resultado de iniciativas de qualidade em hospitais brasileiros. São Paulo, 2003. 46of. Tese (Medicina Preventiva). Faculdade de Medicina, Universidade de São Paulo.
SCHUTZ, A.. Fenomenologia e relações sociais. Rio de Janeiro: Zahar Editores. 1979.319p.

SILVERMAN, D.. Teoría de las organizaciones. Buenos Aires: Editora Nueva Visión. 1975. 301p.

WEBER, M.. Economia e Sociedade. Vol. 1. Brasília, DF: Editora Universidade de Brasília, 1991. 422p.

Recebido em: 10/08/2004

Aprovado em: 20/09/2004 